\title{
A Comparative Study of Rv Function in Anterior And Inferior Stemi
}

\author{
Dr. B. Adilakshmi, M.D, D.M ${ }^{1}$, .Dr. Ram Pakira, M.D; (D.M) ${ }^{2}$, \\ (Associate Professor Of Cardiology, Siddhartha Medical College,Vijayawada, Andhra Pradesh, India.) \\ Senior Resident Cardiology
}

Keywords: Acute MI RV Function, STEMI, MPI, TAM.

\section{Introduction}

The prognosis of patients with acute myocardial infarction (AMI) is directly related to left ventricular (LV) function and size ${ }^{1.2}$ Traditionally, the principal investigated target of clinicians is LV function, with little interest in the right ventricle.However, right ventricular (RV) dysfunction after AMI is also associated with increased risk of morbidity and mortality. ${ }^{3-5} \mathrm{RV}$ dysfunction has been associated with increased morbidity and mortality in patients with congenital heart disease, valvular disease, coronary artery disease, pulmonary hypertension, and heart failure. ${ }^{6-8}$ Right Ventricle (RV) dysfunction may be primarily attributed to abnormality of RV myocardium or secondary to left ventricle (LV) dysfunction, as a consequence of "Ventricular Interdependence" between the two ventricles, as they are encircled by common muscle fibres, share a common septal wall and are enclosed within a common pericardium. ${ }^{9}$ Early recognization of RV dysfunction is warranted but till today it remains a challenging task because of complex structure and asymmetric shape of RV. ${ }^{10}$ Most of the previous studies have evaluated RV functions in patients of inferior myocardial infarction. There are only few studies available in literature evaluating RV function in anterior myocardial infarction. Therefore, in the present study conventional echocardiography combined with tricuspid annular plane systolic excursion [TAPSE Fractional area change(FAC), pulsed doppler and TDI were used to evaluate the effect of different infarction sites on RV functional changes in patients with first acute ST-elevation myocardial infarction (STEMI) without concomitant RV infarction.

The infrastructure for conducting the study is not cumbersome. After taking approval from ethics committee the study was started. Informed consent was taken from patients.

1) To study the RV function in patients with first acute STEMI.

2) To study for any effect on RV function of different infarction sites.

3) To compare the RV function among patients with Anterior STEMI and patients with Inferior STEMI

Detection of a rise and/or fall in cardiac biomarker values preferably Cardiac troponin( cTn), with at least one value above the 99th percentile of the URL and with at least one of the following:

- Symptoms of ischaemia;

- EGG changes indicative of new ischaemia (new ST-T changes or new left bundle branch

block [LBBB]);

- Development of pathological Q waves in the EGG;

- Imaging evidence of new loss of viable myocardium or new regional wall motion

abnormality.

- Identification of an intracoronary thrombus by angiography or autopsy

\section{Rv Anatomy And Physiology}

Normally, the right ventricle is located anterior In the thoracic cavity in relation to the left ventricle, with echocardiographic assessment possible in the 3 traditional acoustic windows (parasternal, apical, and subcostal). The right ventricle is anatomically subdivided into the inflow tract, the infundibulum (outflow tract), and the apex .

Figure 3-RV Anatomy

Nomenclature of

Nomenclature of the right ventricular walls

The current international guidelines recommend the following segmentation of the right ventricular walls: anterior, inferior and lateral walls. The right ventricle also shares the septal wall with the left ventricle. Each 
wall can be divided into 3 segments: basal, mid and apical. The lateral wall is also commonly named "right ventricular free wall".

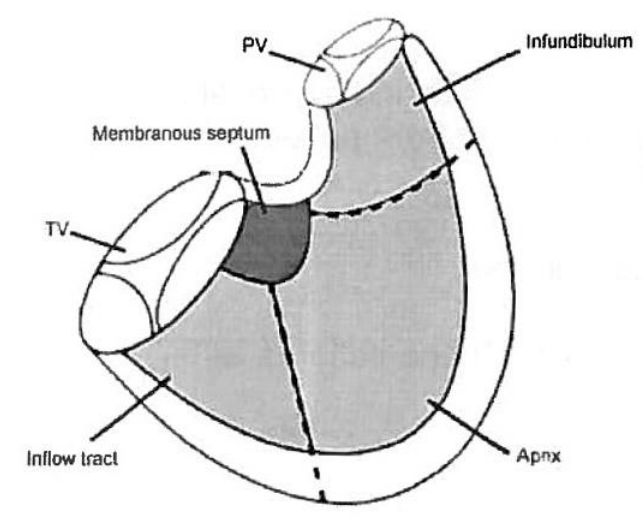

\section{Function of the Right Ventricle}

1)Conduit of blood flow, 2)Maintain adequate pulmonary artery perfusion pressure to improve gas exchange 3) Maintain low systemic venous pressure to prevent congestion of tissues or organs 4)Affect LV function by limiting LV preload in RV dysfunction and Ventricular interdependence 5) Prognostic significance in various clinical settings Ventricular Interdependence

Ventricular interdependence refers to the concept that the size, shape, and compliance of 1 ventricle may affect the size, shape, and pressure-volume relationship of the other ventricle through direct mechanical interactions.

Ventricular interdependence plays an essential part in the pathophysiology of RV dysfunction.

The pericardium may not be as important for systolic ventricular interdependence as it is for diastolic ventricular interdependence. 1 Experimental animal studies showed that approximately $20 \%$ to $40 \%$ of RV systolic pressure and volume outflow results from LV contraction.

The evidence for diastolic ventricular interdependence is well established and based on many experimental and clinical studies. ${ }^{11.12}$ In acute RV pressure- or volume-overload states, dilatation of the RV shifts the interventricular septum toward the left, alters LV geometry, and increases pericardia! constraint.

Conversely, LV volume or pressure overload has also been shown to shift upward the RV diastolic pressure-volume relationship and to redistribute RV filling into late diastole. 30 The parameters to be performed and reported should include a measure of right ventricular (RV) size, right atria! (RA) size, RV systolic function (at least one of the following: fractional area change [FAC], SO, and tricuspid annular plane systolic excursion [TAPSE]; with or without RV index of myocardial performance [RIMP]), and systolic pulmonary artery (PA) pressure (SPAP) with estimate of RA pressure on the basis of inferior vena cava (IVC) size and collapse.

Table 1 - Summary of reference limits for recommended measures of right heartstructure and function

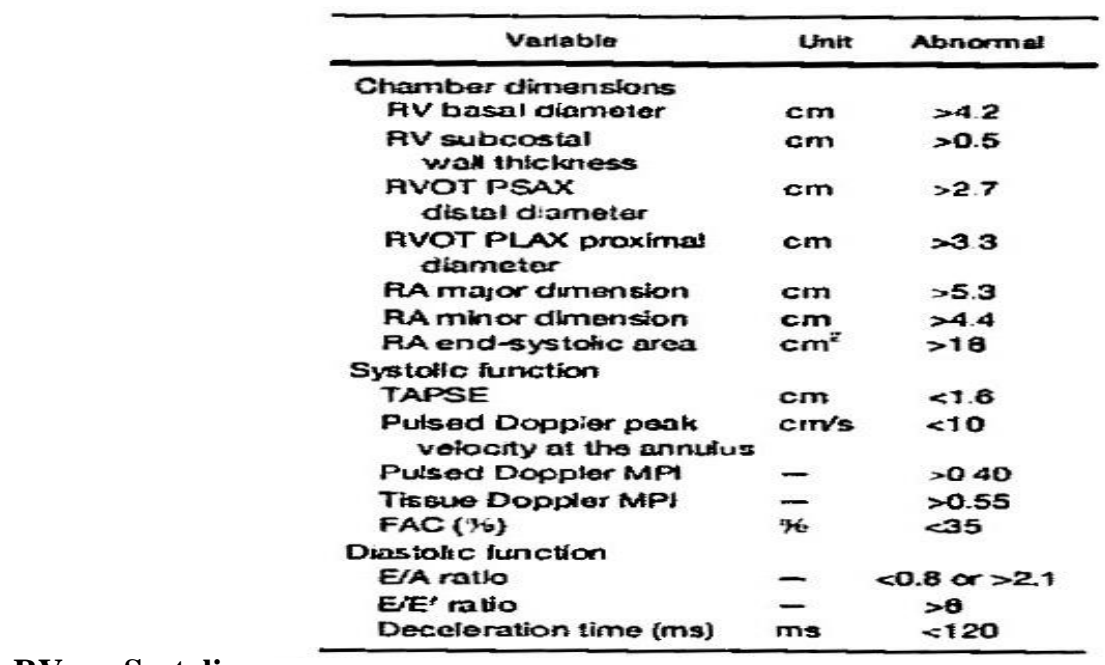

RV Systolic

\begin{tabular}{|c|c|c|}
\hline Variable & Unit & Abnormal \\
\hline \multicolumn{3}{|l|}{$\begin{array}{c}\text { Chamber dimenstorns } \\
\text { AV basal diamoter }\end{array}$} \\
\hline $\begin{array}{l}\text { AV subcostal } \\
\text { wall thickriess }\end{array}$ & $\mathrm{cm}$ & $>0.5$ \\
\hline $\begin{array}{l}\text { RVOT PSAX } \\
\text { distal diameter }\end{array}$ & $\mathrm{cm}$ & $>2.7$ \\
\hline $\begin{array}{l}\text { PVOT PLAX proxima: } \\
\text { diameter }\end{array}$ & $\mathrm{cm}$ & $>3.3$ \\
\hline PA major ctumension & $\mathrm{cm}$ & $>5.3$ \\
\hline $\begin{array}{l}\text { RA minor dimension } \\
\text { RA end-systolic area }\end{array}$ & $\mathrm{cm}^{z}$ & $\begin{array}{l}>4.4 \\
>18\end{array}$ \\
\hline \multicolumn{3}{|l|}{ Systalic function } \\
\hline TAPSE & $\mathrm{cm}$ & $<1.6$ \\
\hline $\begin{array}{l}\text { Pulsed Doppier pank } \\
\text { voiocity at the annulus }\end{array}$ & $\mathrm{cm} / \mathrm{s}$ & $<10$ \\
\hline Pulsea Doppler MPI & - & $>040$ \\
\hline Tisene Doppler MPI & - & $>0.55$ \\
\hline FAC $(36)$ & $\%$ & $<35$ \\
\hline \multicolumn{3}{|l|}{ Dinstolic function } \\
\hline E/A ratlo & - & $<0.8$ or $>2.1$ \\
\hline EfE' ratio & - & $>0$ \\
\hline Deceleration time (ms) & $\mathbf{m s}$ & $<120$ \\
\hline
\end{tabular}

Function. RV 
systolic function has been evaluated using several parameters, namely, RIMP, TAPSE, 2D RV FAC, 2D-RV ejection fraction (EF), three-dimensional (3D) RV EF, tissue Doppler-derived tricuspid lateral annular systolic velocity (SO), and longitudinal strain and strain rate. Among them, more studies have demonstrated the clinical utility and value of RIMP, TAPSE, 2D FAC, and SO of the tricuspid annulus. Although 3D RV EF seems to be more reliable with fewer reproducibility errors, there are insufficient data demonstrating its clinical value at present.

Global assessment of RV function includes the myocardial performance index (MPI), RV dP/dt, RV $\mathrm{EF}$, and FAC . Regional approaches include tissue Doppler-derived and 2D strain, Doppler derived systolic velocities of the annulus (SO), and TAPSE.

\section{RVFAC}

The percentage RV FAC, defined as (enddiastolic area-endsystolic area)/end diastolic area X 100, is a measure of RV systolic function that has been shown to correlate with RV EF by magnetic resonance imaging (MRI). ${ }^{13.14} \mathrm{RV}$ FAC was found to be an independent predictor of heart failure, sudden death, stroke, and/or mortality in studies of patients after pulmonary embolism ${ }^{15}$ and myocardial infarction. ${ }^{16.17}$ FAC is obtained by tracing the RV endocardium both in systole and diastole from the annulus, along the free wall to the apex, and then back to the annulus, along the interventricular septum. Care must be taken to trace the free wall beneath the trabeculations.

Recommendations: Two-dimensional Fractional Area Change is one of the recommended methods of quantitatively estimating RV function, with a lower reference value for normal RV systolic function of $35 \%$.

MPI. The MPI, also known as Tei index, is a global estimate of both systolic and diastolic function of the right ventricle. The MPI is defined as the ratio of isovolumic time divided by ET, or [(IVRT + IVCTJ/ET] or(TCOET/ET).The right-sided MPI can be obtained by two methods: the pulsed Doppler method and the tissue Doppler method. In the pulsed Doppler method, the ET is measured with pulsed Doppler of RV out flow (time from the onset to the cessation of flow), and the tricuspid (valve) closure-opening time is measured with either pulsed Doppler of the tricuspid inflow (time from the end of the trans tricuspid A wave to the beginning of the trans tricuspid E wave) or continuous Doppler of the TR jet (time from the onset to the cessation of the jet). These measurements are taken from different images, and one must therefore attempt to use beats with similar $\mathrm{R}-\mathrm{R}$ intervals to obtain a more accurate RIMP value. In the tissue Doppler method, all time intervals are measured from a single beat by pulsing the tricuspid annulus. As was demonstrated for the LV MPI, ${ }^{36.37 .}$

\section{B. Regional Assessment of RV Systolic Function}

TAPSE or Tricuspid Annular Motion (TAM). TAPSE orTAM is a method to measure the distance of systolic excursion of the RVannular segment along its longitudinal plane, from a standard apical 4-chamber window. TAPSE or TAM represents longitudinal function of the right ventricle. It is inferred that the greater the descent of the base in systole, the better the RV systolic function.

\section{Materials And Methods}

This prospective observational study was performed in the department of Cardiology ICCU, King George Hospital from March 2013 to Feb 2015. Patients admitted to the ICCU within 12 hours of angina onset and hospitalized with a diagnosis of acute STEMI for the first time were included in the study.

The study group comprised 100 Anterior wall STEMI and 50 Inferior wall STEMI patients having history of characteristic ischaemic chest pain (>30 minutes), ECG S/O STEMI and positive serum cardiac markers (CPK$\mathrm{MB}$, trooping $\mathrm{T}$ ) for myocardial necrosis.

All patients were enquired regarding symptoms and examined as per perform enclosed in appendix.

\section{The various baseline characteristics studied include:}

1. Age and Sex of the Patient

2. Window period: time since onset of chest pain to presentation to ICCU

3. Killips class of clinical presentation

4. Diagnosis of AWSTEMIJWSTEMI: detected by means of ECG and echo (hypokinesia / akinesia/dyskinesia of LV) findings.

5. Risk factors:

A. Hypertension - $£ 140 / 90 \mathrm{~mm} \mathrm{Hg}$ (or) on anti hypertensive medication 42

B. Diabetes mellitus (DM) 43: Fasting plasma glucose $2126 \mathrm{mg} / \mathrm{dl}$

2 hr post prandial glucose $£ 200 \mathrm{mg} / \mathrm{dl}$ Symptoms of DM and random plasma glucose concentration $£ 200 \mathrm{mg} / \mathrm{dl}$ Patients on treatment for diabetes mellitus

C. Smoking44: Current or past smokers (those who have quit within the 
past six months)

6. CPK-MB : Samples are taken after $24 \mathrm{hrs}$ of presentation to ICCU, Method adapted was

UV kinetic method .

7. Troponin - T : Samples taken after 24 hrs of presentation to ICCU.

Qualitative estimation done with whole blood Immuno chromatographic method.

8. Electrocardiograms are taken with L\& T VEGA 3 channel EGG machine.

9. Echocardiography;

All the echocardiograms were done on IE 133 Phillips echocardiography Machine within 72 hours after admission.

The echocardiographic parameters evaluated included:

A. LV ejection fraction as impaired LV function $(\mathrm{EF}<55 \%)$ or normal (EFS55\%)45

B. Assessment of regional wall motion abnormalities.

C. Assessment of mechanical defects: mitral regurgitation, tricuspid regurgitation and ventricular septal rupture with the help of color Doppler.

D. The LV dimension and wall thickness were measured from an M-mode recording according to the recommendations of the American Society of Echocardiography. 46 The RV size was assessed at midcavity of RV in the apical 4-chamber view during end-diastole and indexed by the body surface area.

TAPSE was measured from the apical 4-chamber view at the RV free wall level. Puised-wave Doppler flow velocities of LV and RV filling were recorded in the apical 4-chamber view with the sample volume placed between the tips of the mitral and tricuspid valves, respectively.

The following diastolic variables were measured: peak velocities of rapid filling wave (E) and atrial contraction (A), peak El A wave velocity ratio and E-wave deceleration time (DT). Pulsed-wave TDI images were acquired using transducer frequencies of 2.5 to $4.0 \mathrm{MHz}$, adjusting the Nyquist limit to 15 to $20 \mathrm{~cm} / \mathrm{sec}$ and optimizing the gain setting to minimize noise.

From the standard apical 4-chamber view, a 5.2-mm sample volume was placed at the lateral tricuspid annulus, to obtain the spectral pulsed tissue Doppler data. Three cycles were averaged for each TDI measurement. Myocardial peak systolic (Sm), early diastolic (Em) and late diastolic (Am) velocities of RV were measured.

The myocardial relaxation time (RT, the time interval between the end of Sm and the onset of Em), the isovolumic contraction time (IVCT, the time between the end of the Am and the beginning of the Sm) and the ejection time (ET, the time from the beginning to the end of Sm) were used to calculate the TDI-derived LV and $\mathrm{RV}$ myocardial performance indexes (MPI) according to the formula: (IVRT+IVCT/ET). ${ }^{47}$

\section{Inclusion Criteria}

All acute STEMI patients defined by

1) The presence of typical chest pain,

2) ST segment elevation on admission electrocardiograms compatible with $\mathrm{Ml}$,

3) increase of cardiac enzymes in the serum.

Those who were willing to participate in the study

\section{Statistical Analysis}

The observations were recorded in a perform created for this purpose and entered in the master chart created using Microsoft Excel 2007 version. The results were presented in the form of tables and charts and expressed as proportions and percentages. Statistical Analysis was done using SPSS for windows version 21 (SPSS Inc., Chicago, IL). Mean, median, standard deviation and Chi Squares were calculated wherever applicable. t-Test also used wherever applicable. A value of PO.05 was considered statistically significant.

\section{Observations And Results}

Total number of patients were 150(100-AWSTEMI, 50-IWSTEMI).

Table 2- Baseline characters

\begin{tabular}{|l|l|l|l|l|}
\hline S. No & $\begin{array}{l}\text { Baseline } \\
\text { characte }\end{array}$ & AWSTEMI(10 0) & IWSTEM!(50) & P-Value \\
\hline 1 & Males(n) & 86 & 41 & 0.7 \\
\hline 2 & Females(n) & 14 & 9 & 0.7 \\
\hline
\end{tabular}




\begin{tabular}{|l|l|l|l|l|}
\hline 3 & $\begin{array}{l}\text { Mean } \\
\text { Age(Years } \\
\text { HTN\%(n) }\end{array}$ & 53.8 & 56.3 & 0.2 \\
\hline 3 & DM2\%(n) & $18 \%(18)$ & $42 \%(21)$ & 0.9 \\
\hline 4 & Smoking\%(n) & $58 \%(58)$ & $26 \%(13)$ & 0.2 \\
\hline 5 & Alcohol\%(n) & $35 \%(35)$ & $54 \%(27)$ & 0.6 \\
\hline 6 & $\begin{array}{l}\text { Thrombolysis } \\
\%(\mathrm{n})\end{array}$ & $87 \%(87)$ & $36 \%(18)$ & 0.9 \\
\hline 7 & $\begin{array}{l}\text { WP } \\
\text { Hours(Mean) }\end{array}$ & 6.1 & $90 \%(45)$ & 0.5 \\
\hline 8 & & 6.0 & NS \\
\hline
\end{tabular}

There was no significant difference in baseline characters like Gender and risk factors between the two groups ,AWSTEMI and IWSTEMI( M-86 vs 41.F-14 vs 9, P value-0.7). There was no significant difference in mean window period between AWSTEMI and IWSTEMI (6.1 vs6.0).

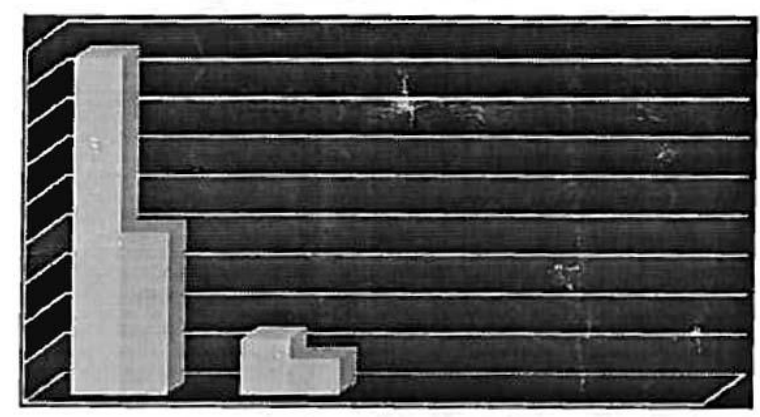

There was no significant difference in mean age between AWSTEMI and IWSTEMI(53.8 vs 56.3).

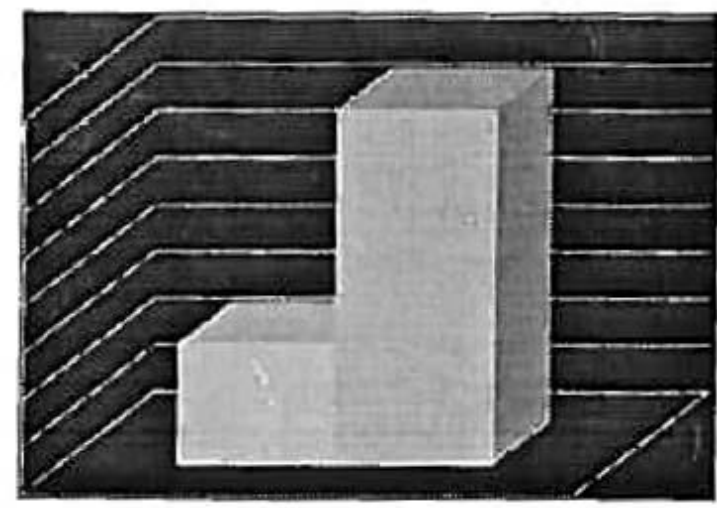

There was no significant difference in Risk factors in both groups AWSTEMI and IWSTEMI like HTN43\%vs42\% (P value -0.9),DM2-18\%Vs26\%(Pvalue-0.2), Smoking-58\% vs 27\% (Pvalue-0.6),Alcohol-35\% vs 36\% (P value-0.9).

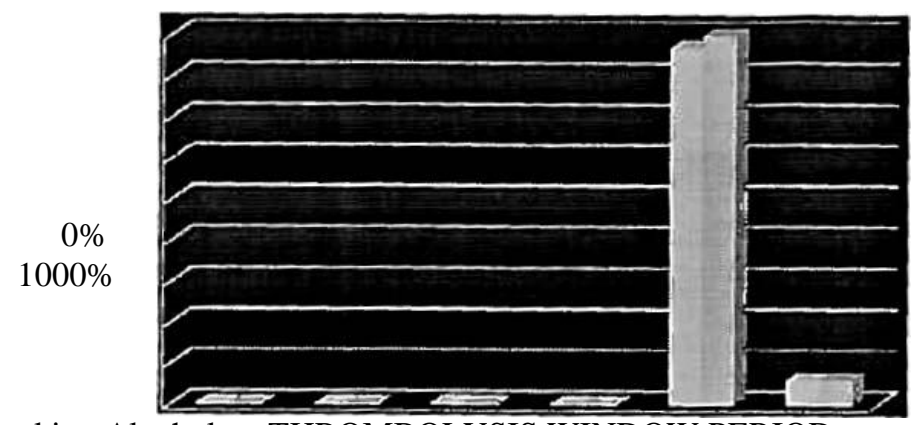

HTN

DM2 Smoking Alcohol THROMBOLYSIS WINDOW PERIOD

$2000 \%$

$3000 \%$

$4000 \%$ 
$5000 \%$

$6000 \%$

$7000 \%$

$8000 \%$

$9000 \%$

Table 3 - Lab Investigations

\begin{tabular}{|l|l|l|l|l|}
\hline S.no & Investigatio ns & AWSTEMI & IWSTEMI & P Vlaue \\
\hline 1 & $\mathrm{HB}(\mathrm{gm} / \mathrm{dl})$ & $13.4 \pm 1.5$ & $13.5 \pm 1.6$ & 0.8 \\
\hline 2 & $\mathrm{RBS}(\mathrm{mg} / \mathrm{d} !)$ & $111.3 \pm 43.6$ & $137.12 \pm 68.9$ & 0.006 \\
\hline 3 & $\mathrm{SCr}(\mathrm{mg} / \mathrm{dl})$ & $0.86 \pm 0.2$ & $0.94 \pm 0.1$ & 0.02 \\
\hline
\end{tabular}

There was significant difference in RBS and S.cr between AWSTEMI and IWSTEMI $\{111 \pm 43.6 \mathrm{vs} 137 \pm 68.9,0.86 \pm 0.94 \pm 0.1\}$ more in AWSTEMI than IWSTEMI but not in $\mathrm{Hb}(13.4 \pm 1.5$ vs $13.5+1.6)$.

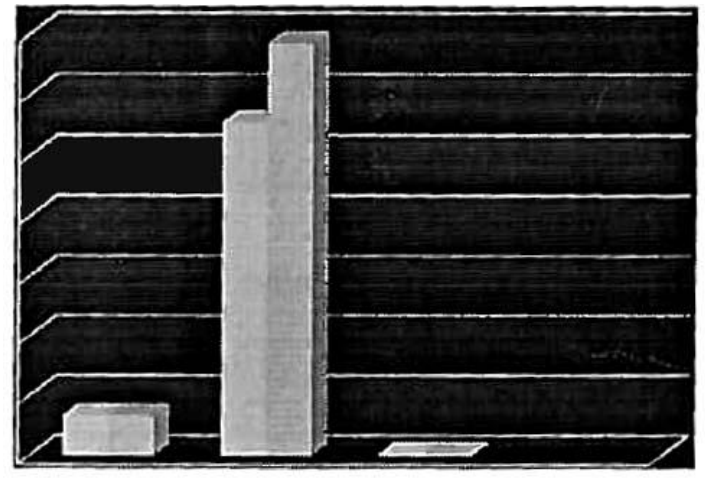

TABLE 4- LV Parameters

\begin{tabular}{|l|l|l|l|l|}
\hline S.no & LV parameter & AWSTEMI & IWSTEMI & P Vlaue \\
\hline 1 & LVIDD $(\mathrm{Cm})$ & $4.7 \pm 0.7$ & $4.7 \pm 0.5$ & 0.9 \\
\hline 2 & LVIDS(Cm) & $3.1 \pm 0.7$ & 3.010 .4 & 0.3 \\
\hline 3 & EF\% & $\wedge 61.018 .1$ & 63.617 .2 & 0.059 \\
\hline 4 & LVE $\{\mathrm{cm} / \mathrm{sec}$ & 60.3116 .7 & $68.2 \pm 17$ & 0.08 \\
\hline 5 & LVA $(\mathrm{cm} / \mathrm{sec})$ & 73.8114 .3 & 71.0112 .0 & 0.2 \\
\hline 6 & E/A & $.85 \pm 0.3$ & .981 .31 & 0.03 \\
\hline 7 & LVDT $(\mathrm{msec})$ & 238.2149 .1 & 206.7148 .5 & 0.00 \\
\hline 8 & LVeSeptum $\{\mathrm{cm} / \mathrm{s} \mathrm{ec})$ & $7.9 \pm 1.7$ & 9.612 .3 & 0.00 \\
\hline 9 & LVE/e & $7.9 \pm 3.1$ & 7.111 .5 & 0.19 \\
\hline
\end{tabular}

$0.98 \pm 0.3,238.2 \pm 49.1 \mathrm{vs} 206.7 \pm 48.5,7.9 \pm 1.7$ vs $\mathbf{9 . 6} \pm \mathbf{2 . 3}$ ) but not in LVIDD.LVIDS, LVEF.LV E Velocity.LV A Velocity LV E/e' between AWSTEMI and IWSTEMI(4.7 \pm 0.7 vs $4.7 \pm 0.5,3.1 \pm 0.7$ vs $\mathbf{3 . 0 \pm 0 . 4 , 6 1 \pm 8 . 1}$ vs63.6 $\pm 7.2,60.3 \pm 16.7$ vs $68.2 \pm 17,73.8 \pm 14$ vs $71.0 \pm 12,7.9 \pm 3.1$ vs $7.1 \pm 1.5$ ).

Table 5- RA and RV Parameters

\begin{tabular}{|c|c|c|c|c|}
\hline S.no & Parameters & AWSTEMI & IWSTEMI & Rvalue \\
\hline 1 & $\begin{array}{l}\text { RA } \quad \text { MAJOR } \\
\text { DIMENSION } \\
(\mathrm{cm})\end{array}$ & $3.9 \pm 0.4$ & $4.0 \pm 0.6$ & 0.08 \\
\hline 2 & $\begin{array}{l}\text { RA } \quad \text { MINOR } \\
\text { DIMENSION }(\mathrm{cm} \\
\text { ) }\end{array}$ & $3.0 \pm 0.5$ & $3.0 \pm 0.5$ & 0.5 \\
\hline 3 & $\begin{array}{l}\text { RA ENDSYSTOLIC } \\
\text { AREA(crm) }\end{array}$ & $11.1 \pm 2.6$ & $11.7 \pm 2.4$ & 0.1 \\
\hline 4 & RVD1(cm) & $2.5 \pm 0.4$ & $2.7 \pm 0.6$ & 0.12 \\
\hline 5 & RVD2(cm) & $2.0 \pm 0.3$ & $2.0+0.48$ & 0.9 \\
\hline 6 & RVD3(cm) & $3.3 \pm 0.6$ & $3.9 \pm 0.9$ & 0.00 \\
\hline
\end{tabular}


Table 6- RV Systolic function

\begin{tabular}{|l|l|l|l|l|}
\hline S.no & Parameters & AWSTEMI & IWSTEMI & P Value \\
\hline 1 & TAPSE(cm) & $1.91 \pm .5$ & $1.8 \pm 0.4$ & 0.6 \\
\hline 2 & $\begin{array}{l}\text { S } \\
\text { VELOCITY }(\mathrm{cm} / \mathrm{s} \mathrm{ec})\end{array}$ & $10.9 \pm 2.4$ & $11.6 \pm 2.7$ & 0.14 \\
\hline 3 & RFAC(\%) & $41.9 \pm 8.7$ & $40.5 \pm 8.5$ & 0.3 \\
\hline 4 & $\begin{array}{l}\text { PULSEDMPI } \\
\text { afmsec) }\end{array}$ & $359.0 \pm 52.0$ & $366.0 \pm 47.4$ & 0.4 \\
\hline 5 & $\begin{array}{l}\text { PULSED } \\
\text { ET(msec) }\end{array}$ & $260.1 \pm 43.5$ & $270.1 \pm 36.4$ & 0.1 \\
\hline 6 & TIE (Pulsed) & $0.36 \pm .13$ & $0.35 . \pm .1$ & 0.5 \\
\hline 7 & TDITCO(msec) & $367.21 \pm 47.6$ & $377.1 \pm 58.0$ & 0.2 \\
\hline 8 & TDIET(msec) & $252.9 \pm 38.5$ & $268.4 \pm 47.0$ & 0.03 \\
\hline 9 & TIE TDI & $0.44 \pm .15$ & $0.40 \pm .13$ & 0.1 \\
\hline
\end{tabular}

Table 7- RV Diastolic function

\begin{tabular}{|l|l|l|l|l|}
\hline S.no & $\begin{array}{l}\text { RV } \\
\text { parameters }\end{array}$ & AWSTEMI & IWSTEMI & P Value \\
\hline 1 & RVE Vel $(\mathrm{cm} / \mathrm{sec})$ & $48.5 \pm 9.1$ & $40.0 \pm 9.8$ & 0.00 \\
\hline 2 & $\begin{array}{l}\text { RVA } \\
\text { vel }(\mathrm{cm} / \mathrm{sec})\end{array}$ & $51.7 \pm 14.6$ & $56 \pm 18$ & 0.6 \\
\hline 3 & RV DT(msec) & $143.0 \pm 19.4$ & $159.0 \pm 16$ & 0.00 \\
\hline 4 & RVE/A & $.81 \pm 0.2$ & $1.8 \pm 0.2$ & 0.1 \\
\hline 5 & Be' (cm/sec) & 5.411 .3 & $4.5 \pm 1.2$ & 0.00 \\
\hline
\end{tabular}

Table 8- RV function

\begin{tabular}{|l|l|l|l|l|}
\hline S.no & Parameters & AWSTEMI & IWSTEMI & P Value \\
\hline 1 & $\begin{array}{l}\text { LV Systolic } \\
\text { dysfunction }\end{array}$ & $11 \%(11)$ & $2 \%(1)$ & 0.055 \\
\hline 2 & $\begin{array}{l}\text { LV Diastolic } \\
\text { dysfunction }\end{array}$ & $85 \%(85)$ & $72 \%(36)$ & NS \\
\hline 3 & $\begin{array}{l}\text { RV systolic } \\
\text { dysfunction }\end{array}$ & $26 \%(26)$ & $22 \%(11)$ & 0.59 \\
\hline 5 & $\begin{array}{l}\text { GradelRV } \\
\text { diastolic } \\
\text { dysfunction }\end{array}$ & $66 \%(66)$ & $86 \%(43)$ & 0.01 \\
\hline 5 & $\begin{array}{l}\text { Grade2RVDiastol ic } \\
\text { dysfunction }\end{array}$ & $33 \%(33)$ & $14 \%(7)$ & 0.01 \\
\hline
\end{tabular}

Table 11 -Comparision between present study and Hsu et al study

\begin{tabular}{|c|c|c|c|c|c|c|c|}
\hline \multicolumn{4}{|l|}{ Hsu et a!49 } & \multicolumn{4}{|c|}{ Present study } \\
\hline CONTROL & AWSTEMI & IWSTE & $\mathrm{P}$ & & VSTEM! & IWSTEM & $\mathrm{P}$ \\
\hline TAPSE & $2.39 \pm .24$ & $2.03 \pm .38$ & $2.12 \pm .28$ & NS & 1.911 .5 & 1.810 .4 & 0.6 \\
\hline \multicolumn{8}{|l|}{$(\mathrm{cm})$} \\
\hline E-wave & $52.9 \pm 8.6$ & 46.118 .5 & $51.3 \pm 8.8$ & NS & 48.519 .1 & $40.0 \pm 9.8$ & 0.00 \\
\hline \multicolumn{8}{|l|}{ velocity } \\
\hline \multicolumn{8}{|l|}{$(\mathrm{cm} / \mathrm{sec})$} \\
\hline $\begin{array}{l}\text { A-wave } \\
\text { velocity }\end{array}$ & $41.1 \pm 9.0$ & 42.U10.9 & $35.3 \pm 7.8$ & $<0.05$ & $61.7 \pm 14.6$ & $56 \pm 18$ & 0.6 \\
\hline \multicolumn{8}{|l|}{$(\mathrm{cm} / \mathrm{sec})$} \\
\hline E/A ratio & $1.3 * 0.2$ & $1.1 \pm 0.3$ & $1.5 \pm 0.4$ & $<0.05$ & $0,81+0.2$ & $1.8+0.2$ & 0.1 \\
\hline E-wave DT & $261.5 \pm$ & 246.41 & $271.2 \pm$ & NS & 143.0119. & $159.0 \pm 16$ & 0.00 \\
\hline (msec) & 35.1 & 59.5 & 36.1 & & & & \\
\hline RVMPI & $0.27 \pm 0.08$ & $0.48 \pm 0.25$ & $0.32 \pm 0.10$ & $<0.05$ & $0,36 \pm .13$ & 0.351 .10 & 0.5 \\
\hline S-velocity & 12.711 .4 & $12.0 \pm 2.8$ & $11.5 \pm 2.6$ & NS & 10.912 .4 & $11.6+2.7$ & 0.14 \\
\hline
\end{tabular}




\section{TAPSE}

In the present study there was no significant difference in TAPSE between AWSTEMI and IWSTEMI $(1.91 \pm .5 \mathrm{vs} 1.8 \pm .4)$

Even Hsu et al also showed that there was no significant difference in TAPSE between AWSTEMI and IWSTEMI $(2.03+0.38$ vs $\mathbf{2 . 1} * \mathbf{0 . 2})$.

\section{Conclusions And Summary}

1. RV Function can be affected not only in IWSTc_MI but also in AWSTEMI.

2. In the present study both RV systolic and diastolic function affected both IWSTEMI and AWSTEMI.

3. There was no statistically significant difference in RV systolic dysfunction between AWSTEMI and IWSTEMI.

4. Grade I RV diastolic dysfunction statistically more in IWSTEMI than AWSTEMI, but Grade II RV diastolic dysfunction more in AWSTEMI than IWSTEMI.

5. So RV function must be assessed not only in IWSTEMI but also in AWSTEMI.

\section{References}

[1]. White HD, Morris RM, Brown MA, et al. Left ventricular endsystolic volume as the major determinant of survival after recovery from myocardial infarction. Circulation 1987; 76:44-51.

[2]. St. John SM, Pfeffer MA, Piappert T, et al. Quantitative twodimensional echocardiographic measurements are major predictors of adverse cardiovascular events after acute myocardial infarction. The protective effects of captopril. Circulation 1994;89:68 -75.

[3]. Mehta S, Eikelboom J, Natarajan M, et al. Impact of right ventricular involvement on mortality and morbidity in patients with inferior myocardial infarction. J Am Coll Cardiol 2001;37:37-43.

[4]. Zehender M, Kasper W, Kauder E, et al. Right ventricular infarction as an independent predictor of prognosis after acute inferior myocardial infarction. N Eng J Med 1993;328:981- 8.

[5]. Zornoff LA, Skali H, Pfeffer MA, et al. Right ventricular dysfunction and risk of heart failure and mortality after myocardial infarction. J Am Coll Cardiol2002;39:1450-5.

[6]. Matthews JC, Dardas TF, DorschMP, Aaronson KD. Right-sided heart failure: diagnosis and treatment strategies. Curr Treat Options Cardiovasc Med 2008; 10:329-41,

[7]. De Groote P, Millaire A, Foucher-Hossein C, Nugue O, Merchandise X, Ducloux G, et al. Right ventricular ejection fraction is an independent

[8]. Voekel NF, Quaife RA, Leinwand LA, Barst RJ, McGoon MD, Meldrum DR, et al. Right ventricular function and failure: report of a National Heart, Lung, and Blood Institute and working group on cellular and molecular mechanisms of right heart failure. Circulation2006;114:1883-91.

[9]. Santamore WP, Gray Laman.Significant left ventricular contributions to right ventricular systolic functions.Chest 2005; 107:1134-45.

[10]. Miller D.Farah MG, Liner A.fox Keith, Schluchter M, Hoit BD.The relation between quantitiative right ventricular ejection fraction and indices of tricuspid annular motion and myocardial performance index. J.Am.Soc.Echocardiogr2004;17:443-7.

[11]. Santamore WP, Dell'ltalia LJ. Ventricular interdependence: significant left ventricular contributions to.right ventricular systolic function. Prog Cardiovasc Dis. 1998:40:289-308.

[12]. Taylor RR, Covell JW, Sonnenblick EH, Ross J Jr. Dependence of ventricular distensibility on filling of the opposite ventricle. Am J Physiol. 1967; 213: 711-718.

[13]. Lai WW, Gauvreau K, Rivera ES, Saleeb S, Powell AJ, Geva T. Accuracy of guideline recommendations for two-dimensional quantification of the right ventricle by echocardiography. Int J Cardiovasc Imaging 2008;24: 691-8.

[14]. Anavekar NS, Gerson D, Skali H, Kwong RY, Yucel EK, Solomon SD. Two- dimensional assessment of right ventricular function; an echocardiographic- MRI correlative study. Echocardiography 2007;24: 452-6.

[15]. Nass N, McConnell MV, Goldhaber SZ, Chyu S, Solomon SD. Recovery of regional right ventricular function after thrombolysis for pulmonary embolism. Am J Cardiol 1999;83:804-6.

[16]. Zornoff LA, Skali H, Pfeffer MA, St John SM, Rouleau JL, Lamas GA, et al. Right ventricular dysfunction and risk of heart failure and mortality after myocardial infarction. J Am Coll Cardiol 2002;39:1450-5.

[17]. Anavekar NS, Skali H, Bourgoun M, Ghali JK, Kober L, Maggioni AP, et al. Usefulness of right ventricular fractional area change to predict death, heart.

[18]. Rojo EC, Rodrigo JL, Perez de Isla L, Almeria C, Gonzalo N, Aubele A, et al. Disagreement between.tissue Doppler imaging and conventionalpulsed wave Doppler in the measurement of myocardial performance index. Eur J Echocardiogr 2006;7:356-64.

[19]. Gaibazzi N, Petrucci N, Ziacchi V. Left ventricle myocardial performance index derived either by conventional method or mitral annulus tissue- Doppler: a comparison study in healthy subjects and subjects with heart failure. J Am Soc Echocardiogr 2005; 18:1270-6. 